\title{
Vibration of the steel frame of the primary sand classifier
}

\author{
Josef Soukup ${ }^{1, *}$, Blanka Skočilasová ${ }^{1}$, Jan Skočilas $^{2}$ \\ ${ }^{1}$ Faculty of Production Technology and Management, J. E. Purkyne University in Usti nad Labem. \\ Pasteurova 3334/7, 40096 Usti nad Labem. Czech Republic \\ ${ }^{2}$ Czech Technical University in Prague, Faculty of Mechanical Engineering, Department of Process \\ Engineering, Technická 4, 16607 Praha 6, Czech Republic
}

\begin{abstract}
Article deals with the presentation of measurement that have been carried out on the steel frame of the primary sand classifier. The aim of the investigation was to identify the sources of the abnormal vibration of the frame. The vibration significantly reduces the effective performance of the classifier. The frame anchorage has been stripped out from concrete footing by these vibrations. The measurement of dynamic properties of the frame were performed. The displacements of the particular trusses have been experimentally investigated by accelerometers. The tensile test were performed in the places of expected maximum amplitude of the vibration. Based on the experiment results and new design calculation of the steel frame (truss construction), the new construction design was developed and improved by frame reinforcing. The new designed construction was investigated by vibration measurements again. The acceleration and total amplitude of particular trusses were recorded. The steel construction of the supporting frame has frequencies in range from 13.07 to $13.10 \mathrm{~Hz}$. The significant enhancement of the noise and vibration of the main bearing have been observed during the classifier operation. The system of precautions was proposed to improve operation of the classifier and after realization the classifier run with no limitation.
\end{abstract}

Keywords: vibration, frame, acceleration, steel structures

\section{Introduction}

The reduction of the maximum amplitude of the vibration of the rigid construction and related noise is an optimization process which can be solved by several methods, e.g. experimental or numerical [1]. The improvement of the measuring methods or developing new methods of measurement allows to obtain more detailed or high accuracy information about investigated systems [2 - 4]. For the numerical simulation the actual common methods are used for investigation of the dynamic system, e.g. SEM or FEM [5]. The nowadays dynamic system observation has been based on classical approach of identification of the modal parameters of the system [6]. By increasing the computing capabilities, the new algorithms of numerical methods were developed, e.g. OKID [7],

\footnotetext{
* Corresponding author: josef.soukup@ujep.cz

Reviewers: Robert Grega, Ján Vavro Jr.
} 
MLK [8] or FDD [9]. But usually the customer needs the analysis and improvement of the system in very short period. In such cases there is no time for numerical study and its validation. Therefore this study is pure experimental and arises from preliminary analysis [10]. From measurements the new design construction is proposed and validated its positive effect on the noise and vibration reduction.

The technological line for exploited gravel sand treatment consists of two vibrating classifiers, a coarse (with sand washer) and fine one; the screens are fitted with the respective conveying routes (belt conveyors). The gravel sand is exploited from water using a chain-bucket dredger, conveyed by the belt conveyor to the technical facility of the sand pit where the above-mentioned classifiers and aggregate yards are located.

The excavated gravel sand is conveyed by the $800 \mathrm{~mm}$ wide and $40 \mathrm{~m}$ long belt conveyor to a METSO CVB 2661 III spraying coarse vibrating classifier; the sand then travels from the classifier to a two-shaft knife washer. Big rocks are conveyed from the classifier to the rock crusher, from where the crushed rocks return to the coarse classifier, non-crushed rocks are sorted and stored for other purposes. The sand is conveyed from the coarse classifier by a steep $650 \mathrm{~mm}$ wide and $27 \mathrm{~mm}$ long conveyor to another METSO CVB 2050 III spraying vibrating classifier (not subject of the design) that classifies the sand to the individual fractions, storing them in the sand year by fraction.

In operation, the coarse classifier makes high vibrations, which are transmitted by the steel structure to the foundations and further to its surroundings. Vibrations are caused by the crusher itself; high structural deviations reducing durability of the classifier bearings.

The facility operator requested the measurement of the steel structure and casing and mechanism vibrations of the coarse classifier.

The steel structure is anchored to the reinforced-concrete foundation slab. Drawing documentation of the reinforced-concrete slab was not provided. According to the investor and findings noted in the submitted technical documentation, the reinforced-concrete slab is $1,000 \mathrm{~mm}$ thick, anchoring axes of supporting posts are spaced in the longitudinal direction at $4,800 \mathrm{~mm}$ and $3,900 \mathrm{~mm}$, the total span between the end posts is $8,700 \mathrm{~mm}$. Anchoring axes of the posts in the transversal direction are spaced at $3,230 \mathrm{~mm}$, the post base is 400 $\mathrm{mm}$ wide, total anchoring width is $3,630 \mathrm{~mm}$ (total foundation slab width in transversal direction is $4,200 \mathrm{~mm}$ ). The steel structure scheme is shown in Figure 1.

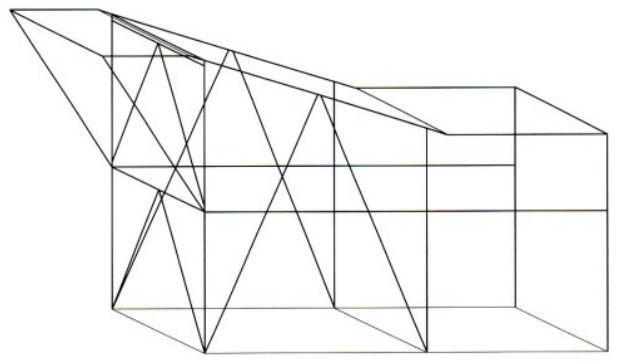

Fig. 1. Classifier steel structure scheme

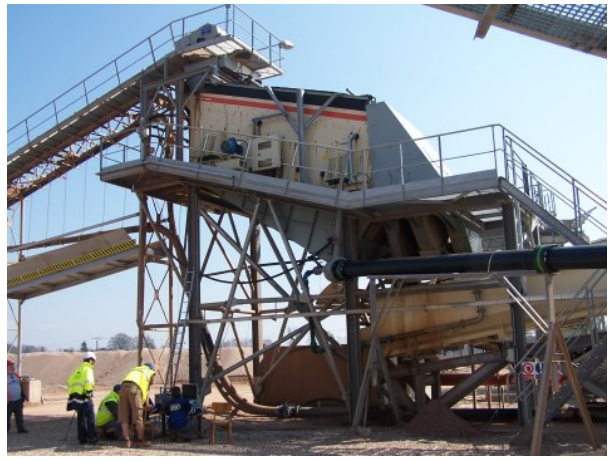

Fig. 2. View of the classifier

The classifier supporting structure consists of 6 posts with transversal and longitudinal spokes. The classifier is placed on longitudinal spokes. A gallery is attached to the consoles around the classifier (on spokes). The walkway floor is made from floor grids; the walkways and gallery are fitted with railing. Posts have foundation slabs, anchored to the foundation using pasted-in HILTI M30 anchors (effective anchoring depth is $270 \mathrm{~mm}$ ). The posts are made from HEB 240 profile (classifier installation); the main longitudinal spokes 
from profile HEB 240, HEA 160, U 240, U 200. Post height in longitudinal direction (3 posts) varies. Post 1 (the longest one) is $6,574 \mathrm{~mm}$ long, post 2 (the middle one) is 5,018 $\mathrm{mm}$ long, post 3 is $4,780 \mathrm{~mm}$ long.

The main longitudinal spoke is a welded assembly of 3 parts, welded from HEA 240 profile. The oblique part (according to placement on posts) is $6.147 \mathrm{~mm}$ long, 2 pieces (one from each side) made from HEA 240 profile with the length of $1,938 \mathrm{~mm}$ are welded to it (free bearing on the tallest post) and $2,990 \mathrm{~mm}$ in case of the shortest post. Welding is missing in the support area (in the centre of the post); the posts are missing in area of the classifier supports. The steel structure is made of S235 galvanised steel.

Empty coarse classifier placed on the steel structure weighs $12,640 \mathrm{~kg}$, material inside the classifier weighs 1,500 to $2,000 \mathrm{~kg}$ (depends on the filling of the classifier).

\section{Methodology}

Regarding the fact that during the first assessment, the steel structure displayed design errors, the requirements for steel structure completion were not met, particularly the requirements for completing nodal points, completing transversal spatial reinforcements, spatial dimensioning (too narrow structure), insufficient dimensions of foundation slam, etc.

Sub-base in the area of the classifier steel structure contains an approx. $1 \mathrm{~m}$ layer of floury soil with gravel sand underneath with the thickness of as much as $12 \mathrm{~m}$ and the underground water level reaches as high as to the floury soil (almost to the surface in the areal of the borrow pit). As the steel structure vibrations are transmitted to the surroundings, it was not possible to directly measure the steel structure deviations.

The measurement methodology has been processed, dividing the measurements into 3 stages. In stage 1, an indicative measurement of acceleration on one web was conducted, based on which the acceleration measurement methodology was drafted. This indicative measurement provided the initial information about the steel structure vibrations, in particular, about the frequency and dominating direction of oscillation. It was determined that the steel structure oscillation frequency is $13 \mathrm{~Hz}$ in constant operation of the classifier, the main oscillation direction is along the transversal axis. The frequency of the frame resonance was identified during the classifier deceleration and fixed at $10 \mathrm{~Hz}$. Regarding the fact that the classier driving motor speed cannot be adjusted, it is impossible to state with certainty that the frequency of $13 \mathrm{~Hz}$ is the frequency of resonance.

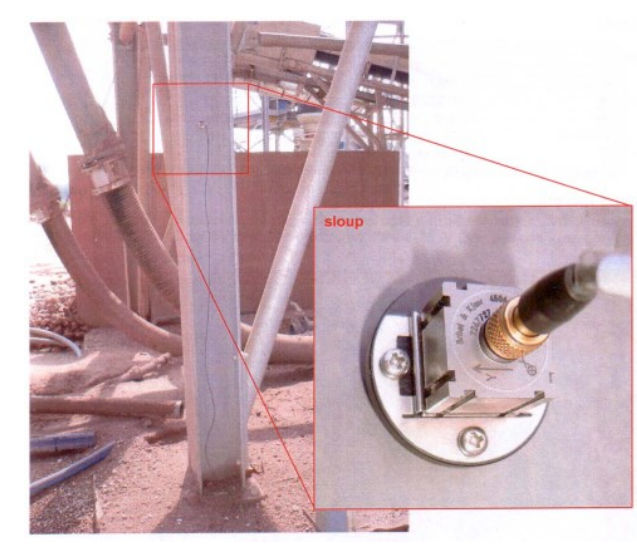

Fig. 3. Location of the 3-axis acceleration sensor

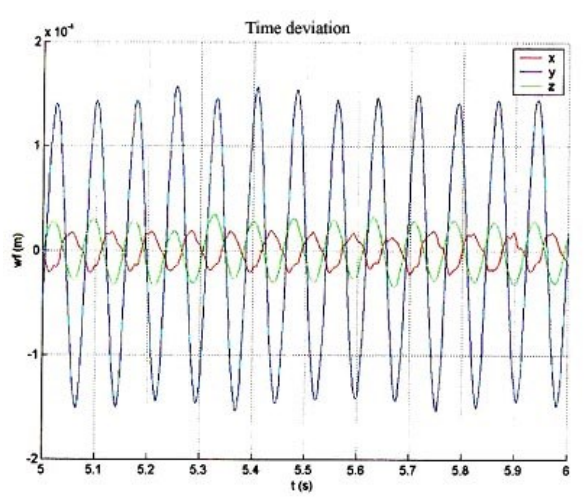

Fig. 4. Time progression of deviation 


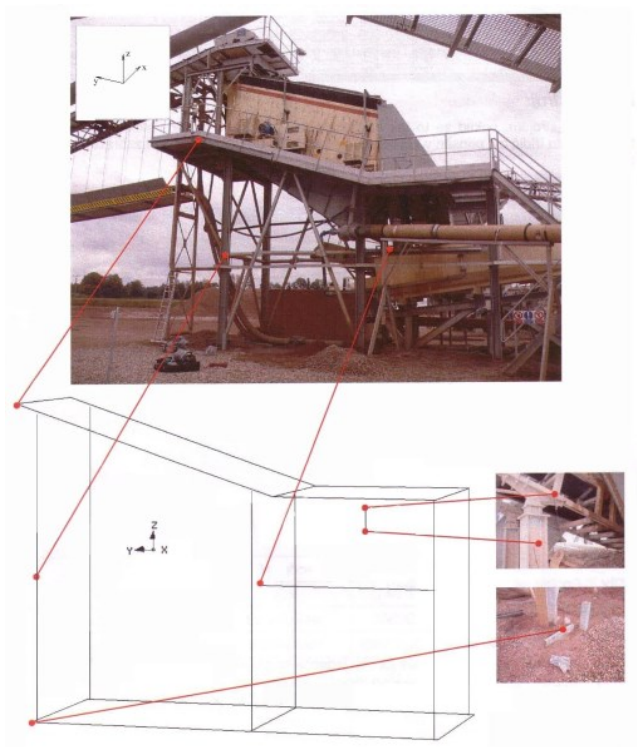

Fig. 5. Acceleration (shift) measurement model

Based on the above-mentioned measurement, a more detailed measurement was subsequently conducted, using Brül\&Kjaer three-axis (4506 type, 2 pcs) and single-axis (4507 B004 type, 2 pcs) accelerometers with a PULSE (6/1) analyser, type $3560 \mathrm{C}$.

A reference accelerometer was installed on the rear post to measure acceleration along the axis. Another 3 accelerometers were relocated during the classifier steel structure measurement as required. Effective deviation values (RMS) were recorded, including their spectrum and wave shape. Maximum deviations occurred at the frequency of $13 \mathrm{~Hz}$.

Another step was strain measurement. The measurement was conducted using HBM strain gauges, type 1-LY11-10/20, with an active length of $10 \mathrm{~mm}$, resistance of $120 \Omega$, application of Z70 bonding agent.

This measurement was used to determine the steel structure oscillation frequency of $13.1 \mathrm{~Hz}$ (FFT analysis which indicates whether it is the dominating frequency), maximum stress range $17.92 \mathrm{MPa}$. In terms of strength, the structure is compliant, which is normal in such situations.

These measurements indicate that the steel structure is a little rigid in the horizontal plane ( $x, z$ axes) and it was recommended to reinforce the structure.

Regarding the fact that it was impossible to prepare a brand new design of the steel structure for operating and economic reasons, we did the new (static and dynamic) calculation and proposed a design adjustment.

The steel structure supplier performed internal reinforcement of the structure by inserting diagonal reinforcements in the structure (Figure 6). However, the reinforcement was performed inconsistently with the recommendation, conditions for lattice work were not met, nodal points were not created, etc. This introduced torsional and bending stress to the structure.

\section{Experimental examination of reinforced steel structure}

Acceleration values at selected points were measured on the reinforced steel structure. Deviations were then determined by integration (the direct determination of deviations was impossible to perform due to vibrations in the surroundings). For purposes of acceleration measurement, points between the steel structure nodes were selected so that shifts can be determined in the next step if it turns out to be meaningful (for eventual further specification of results). Acceleration in the selected points was measured in dependence on movement of the classifier (identical time axis). Measurement was conducted using 7 single-axis acceleration sensors, of which one was always installed on the classifier. The other 6 sensors were installed in various points on the steel structure (see the respective figures of the layout in the text to follow). There were 6 measurements conducted (according to layout of sensors), each measurement for 3 conditions of classifier operation

a) classifier start-up (marked x-1), 
b) operation with material (marked x-2),

c) machine deceleration without material (marked $x-3)$,

where $x$ is the sequence number of measurement (from 1 to 6 ). The individual sensors are numbered from 0 to 6 . Measurement time was fixed at 20 seconds. Measurement was conducted with the use of:

- Type HBM B12/200acceleration sensors, serial No. 51587, 073810245, 073810249, 073810242, 52918, 110410320, 104810051. All sensors have been calibrated

- measuring AD card NI 6225, serial No. 121B821 (HA 4198431) - calibrated

- standard laptop.

Figures 6 and 7 show positioning of acceleration sensors in 2 measurement cases (cases 1 and 6)

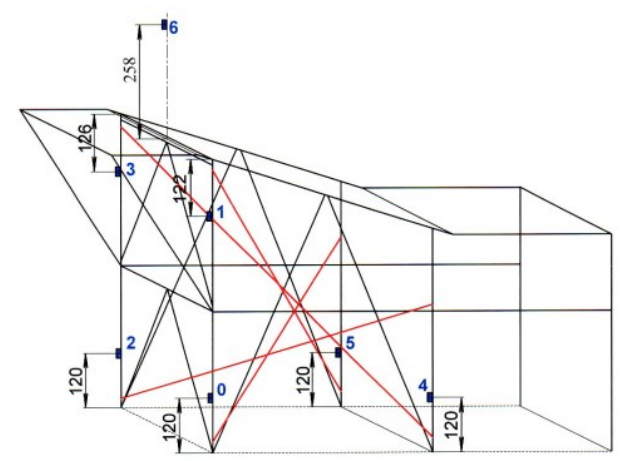

Fig.6. Reinforced steel structure scheme Location of acceleration sensors measurement 1

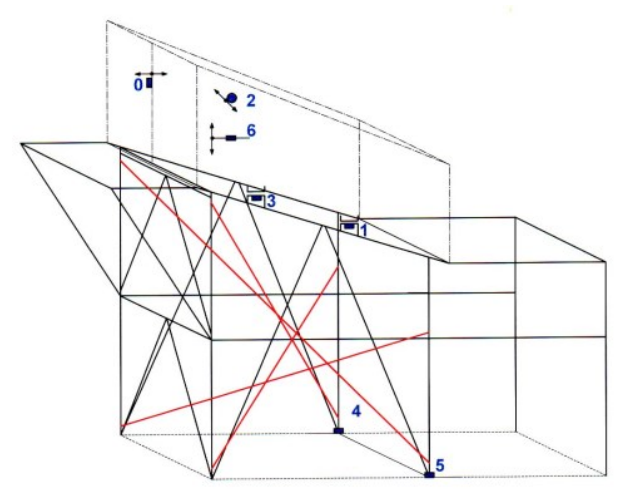

Fig. 7.Reinforced steel structure scheme Location of acceleration sensors measurement 6

Loading forces of the steel structure from the classifier were determined based on maximum and minimum values of acceleration

$$
F=m \cdot a
$$

where $F$ - force $[\mathrm{N}], m-$ mass $[\mathrm{kg}], a$ - acceleration $\left[\mathrm{ms}^{-1}\right]$.

The forces were determined in both the horizontal direction $(x, y)$ and in vertical the direction $(z)$, where the vertical acceleration values were measured (measurements 4,5 and 6). The forces were determined based on the amount of the raw material in the classifier, which was determined from the classifier output. Weight during operation with material is based on the line output $\left(1,000\right.$ t.hour ${ }^{-1}$ i.e. about $\left.0.3 \mathrm{t} . \mathrm{s}^{-1}\right)$. The gravel sand holding time in the classifier is about 5-6 seconds.

The graphical acceleration presentation (Figures 8-10) only includes a part of the measured values, however, they always include the critical section. They show the acceleration trend for sensors 0 and 1 according to Figure 6 . This is acceleration along the $x$ axis on the same web in different heights from the foundation (the distance from the foundation and upper web end is shown in Figure 6). 

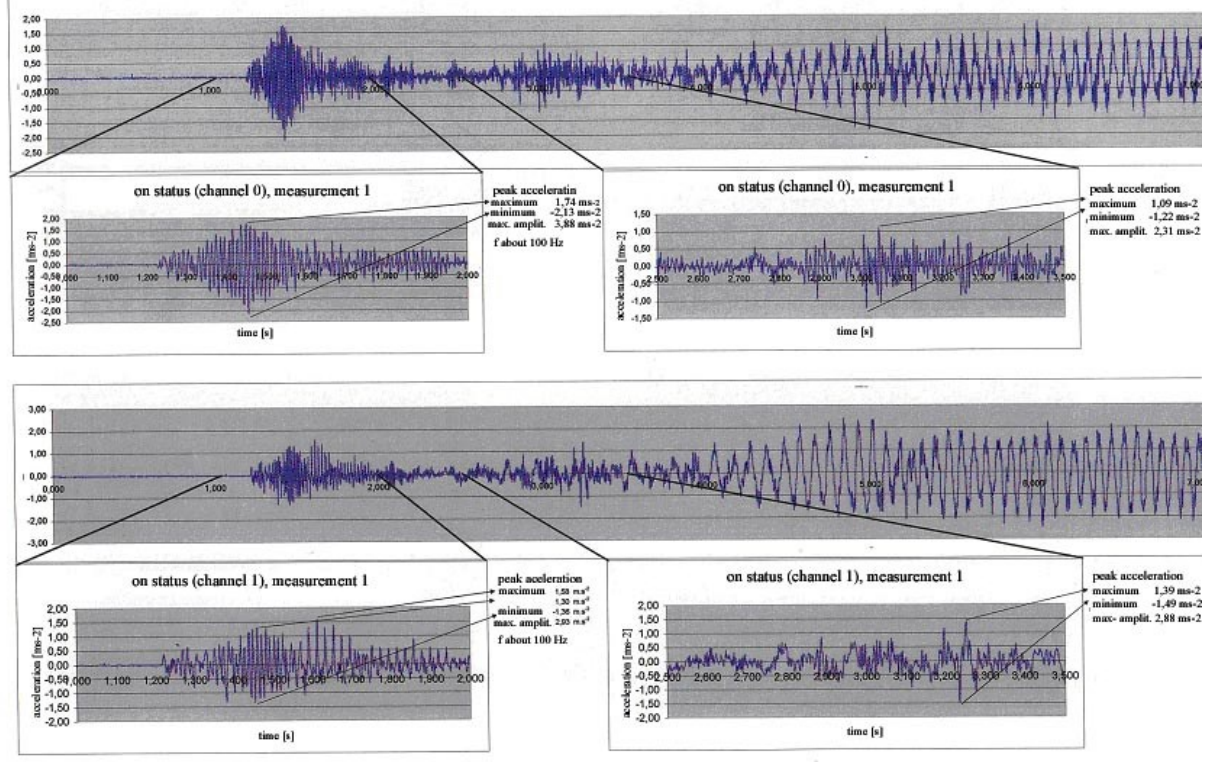

Fig. 8. Measurement 1 - classifier start-up, sensor 0 (up) and 1 (down)

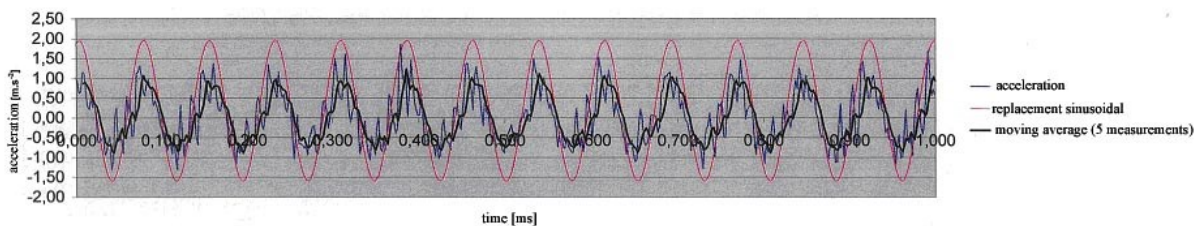

measurement 1 , channel 1

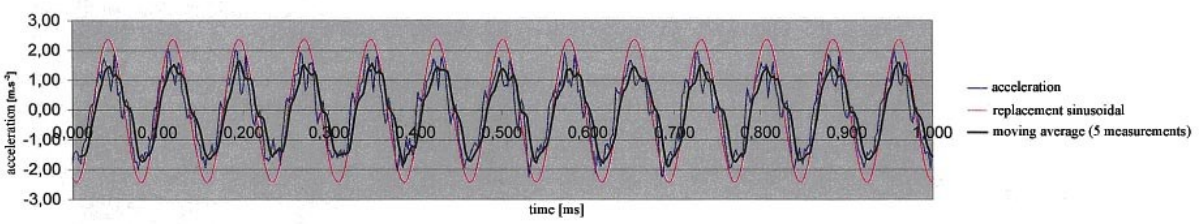

Fig. 9. Measurement 1 -- classifier operation with material, sensor 0 (up) and 1 (down)

The above-mentioned figures indicate that during the classifier start-up (Figure 8), increasing speed results in a sharp increase in acceleration; acceleration decreases after passing the frequency of resonance, and increases again afterwards. Similar behaviour can be observed in all sensors. Classifier operation with material (i.e. after screens are loaded) is evidently smoother. The acceleration trend essentially copies the classifier shaft speed (Figure 9).

A big vibration of the steel structure is evident during the classifier deceleration (Figure 10) before stopping. Even after the classifier stops (about 2,800 seconds), damping occurs fast, whereas acceleration again increases in more than 10 seconds. The steel structure stops vibrating in about 18 seconds.

Maximum and minimum values of acceleration, oscillation, amplitude, mean value and acting forces were evaluated (only on the classifier). Table 1 shows the characteristic values of acceleration for measurements 1 and 6 for all sensors. 

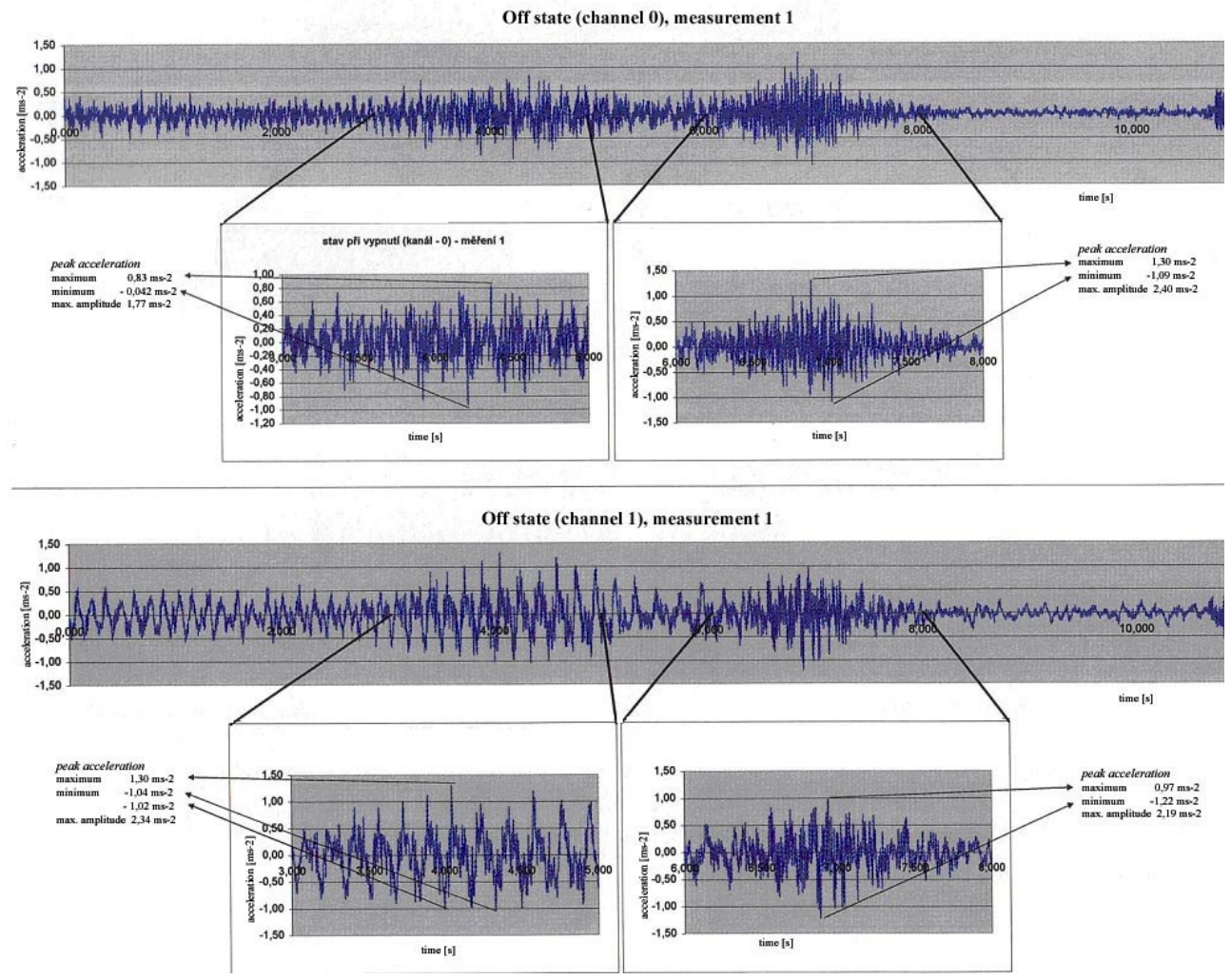

Fig. 10. Measurement 1, classifier deceleration Sensors 0 (up) and 1 (down)

Table 1. Acceleration values of the individual sensors in measurements 1 and 6

\begin{tabular}{|c|c|c|c|c|c|c|c|c|}
\hline \multirow[t]{2}{*}{ Acceleration } & \multirow[t]{2}{*}{ Unit } & \multicolumn{7}{|c|}{ Sensor } \\
\hline & & $\mathbf{0}$ & 1 & 2 & 3 & 4 & 5 & 6 \\
\hline \multicolumn{9}{|c|}{ Measurement 1} \\
\hline \multicolumn{9}{|c|}{ Classifier start-up (without material) } \\
\hline$a_{\max }$ & $m \cdot s^{-2}$ & 1.74 & 1.58 & 1.17 & 0.82 & 1.93 & 2.57 & 3.11 \\
\hline$a_{\min }$ & $\mathrm{m} \cdot \mathrm{s}^{-2}$ & 2.13 & 1.36 & 1.19 & -0.85 & -1.25 & -2.44 & -3.67 \\
\hline \multicolumn{9}{|c|}{ Classifier operation with material interval $0.0-1.0$ second } \\
\hline$a_{\max }$ & $\mathrm{m} \cdot \mathrm{s}^{-2}$ & 1.85 & 2.09 & 0.32 & 2.28 & 1.90 & 2.11 & 29.94 \\
\hline$a_{\min }$ & $\mathrm{m} \cdot \mathrm{s}^{-2}$ & -1.16 & -2.05 & -3.27 & -1.71 & -2.14 & -1.79 & -30.68 \\
\hline \multicolumn{9}{|c|}{ Classifier deceleration interval 3.0-5.0 seconds } \\
\hline$a_{\max }$ & $m \cdot s^{-2}$ & 0.83 & 1.30 & 1.44 & 1.49 & 1.40 & 3.30 & $*$ \\
\hline$a_{\min }$ & $\mathrm{m} . \mathrm{s}^{-2}$ & -1.09 & -1.04 & -1.50 & -1.75 & -1.70 & 3.49 & \\
\hline \multicolumn{9}{|c|}{ Measurement 6} \\
\hline \multicolumn{9}{|c|}{ Classifier start-up (without material) } \\
\hline$a_{\max }$ & $\mathrm{m} \cdot \mathrm{s}^{-2}$ & 3.28 & 0.79 & 1.84 & 4.52 & 0.20 & 1.23 & 1.40 \\
\hline$a_{\min }$ & $m \cdot s^{-2}$ & -3.08 & -0.75 & -1.74 & -6.64 & -0.17 & -0.87 & -1.20 \\
\hline \multicolumn{9}{|c|}{ Classifier operation with material interval $0.0-1.0$ second } \\
\hline$a_{\max }$ & $m \cdot s^{-2}$ & 47.11 & 0.94 & 3.01 & 1.46 & 0.51 & 1.33 & 42.12 \\
\hline$a_{\min }$ & $\mathrm{m} \cdot \mathrm{s}^{-2}$ & -42.91 & -1.25 & -3.62 & -1.99 & -0.31 & -0.97 & -41.03 \\
\hline
\end{tabular}


Table 1. (continued)

\begin{tabular}{|c|c|c|c|c|c|c|c|c|}
\hline \multirow[t]{2}{*}{ Acceleration } & \multirow[t]{2}{*}{ Unit } & \multicolumn{7}{|c|}{ Sensor } \\
\hline & & $\mathbf{0}$ & 1 & 2 & 3 & 4 & 5 & 6 \\
\hline \multicolumn{9}{|c|}{ Classifier deceleration interval 4.0-5.0 seconds } \\
\hline$a_{\max }$ & $m \cdot s^{-2}$ & 10.15 & 0.96 & 0.91 & 0.79 & 0.21 & 0.67 & 17.25 \\
\hline$a_{\min }$ & $\mathrm{m} \cdot \mathrm{s}^{-2}$ & -9.61 & -0.88 & -1.61 & -0.71 & -0.23 & -0.65 & -12.96 \\
\hline
\end{tabular}

$a_{\max }-$ maximum acceleration value

$a_{\min }-$ minimum acceleration value

The acceleration trend on sensors 2 (transversal acceleration of classifier casing) and 3 (vertical acceleration in classifier placement on supporting steel structure under silentblocks) is shown in Figures 11-13.

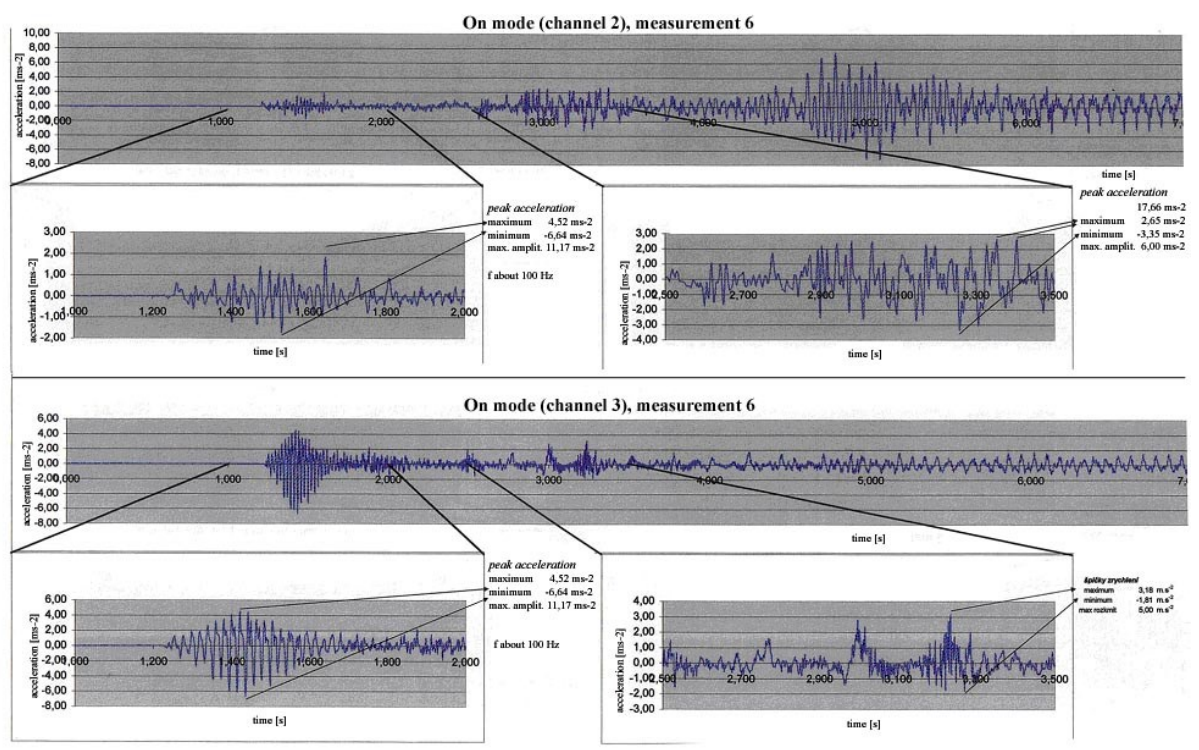

Fig. 11. Measurement 6 - classifier start-up, sensor 2 (up) and 3 (down)
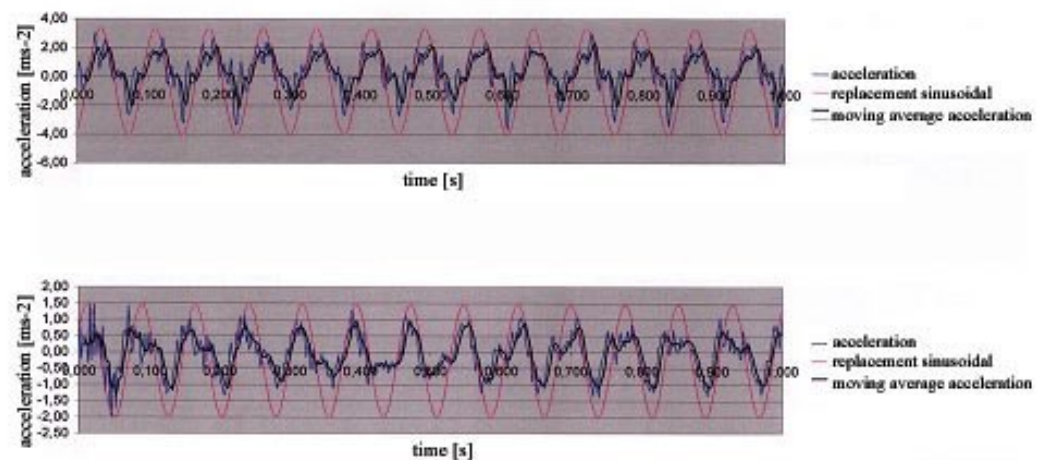

Fig. 12. Measurement 6 - with material, sensor 2 (up) and 3 (down) 

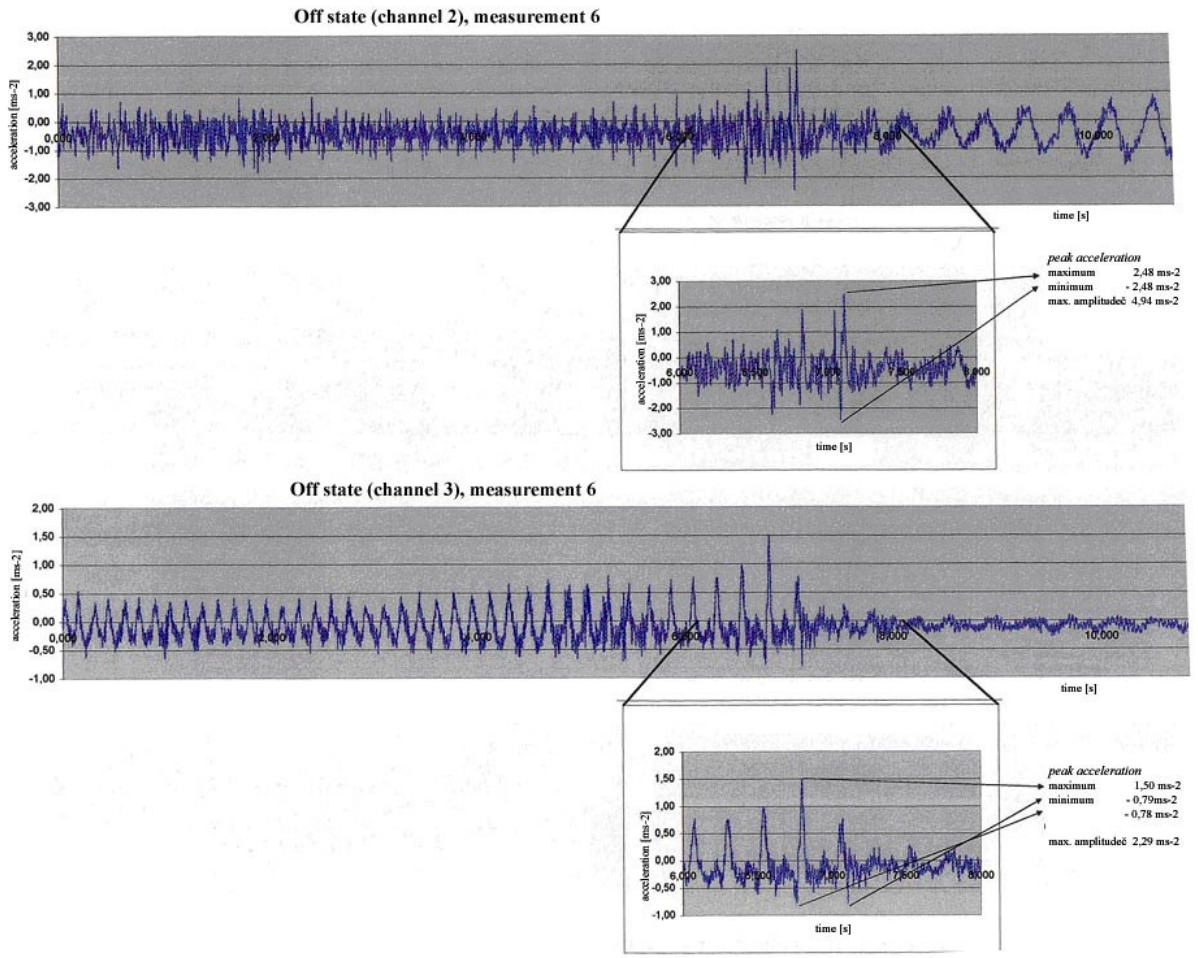

Fig. 13. Measurement 6 - classifier deceleration, sensor 2 (up) and 3 (down)

\section{Conclusion}

The measurement results indicate that the frequency of the entire structure oscillation ranges from 13.07 to $13.1 \mathrm{~Hz}$ in all measurement cases, which demonstrates that all measurements are commensurable.

Although the steel structure of the CVB 2661 III classifier was made stronger (reinforced), which definitely reinforced the entire structure, we have reservations about its structural design, which was also confirmed by the measurements. The structure rigidity in the horizontal plane (along both axes) is low, mainly in the transversal direction. The structure is too narrow with respect to the acting load and height.

Due to the low rigidity of the structure, big deviations occur on its upper side, which are amounting to $\pm 12.5 \mathrm{~mm}$ in transversal direction on the longest web. This results in big acceleration and thus in big forces produced by the classifier operation, acting on the steel structure. Measurements on the bases of the steel structure indicate that the steel structure is affected by torsional forces; vertical forces in bases against the anchorage are too high (see the new stress analysis).

New static calculation of the entire reinforced steel structure was conducted, also considering dynamic forces from acceleration as the input values of forces from the classifier in addition to the dead weight. 
This new calculation indicates that the steel structure is compliant in terms of strength; however, the structure deflection is not compliant. This is the reason why it was recommended to refit all internal reinforcements of the steel structure according to the original proposal (create nodal points) and design the steel structure reinforcement from the outside. This will require the foundation slab to be expanded for purposes of brace anchoring.

Insufficient rigidity of the steel structure and thus high values of vibrations result in the limited durability of the main shaft bearings of the coarse gravel sand classifier.

\section{References}

1. V. Wowk, Machinery vibration: measurement and analysis. Boston: McGraw-Hill, 358 p., ISBN 0-07-071936-5, (1991)

2. S. P. Hyo, P. Keunhyoung, K. Yousok, W. Ch. Se, Deformation Monitoring of a Building Structure Using a Motion Capture System. IEEE/ASME Transactions on Mechatronics 20 (5), 2276-2284 (2014)

3. T. U. Yılmaz, U. O. Özugurel, K. Bulut, M. N. Inci, Vibration amplitude analysis with a single frame using a structured light pattern of a four-core optical fibre. Optics Communications 249 (4-6), 515-522 (2005)

4. D. Zhu, J. Guo, Ch. Cho, Y. Wang, K. Lee, Wireless Mobile Sensor Network for the System Identification of a Space Frame Bridge. IEEE/ASME Transactions on Mechatronics 17 (3), 499-507 (2012)

5. S. L. Zuo, F. M. Li, Ch. Zhang, Numerical and experimental investigations on the vibration band-gap properties of periodic rigid frame structures. Acta Mechanica 227 (6), 1653-1669 (2016)

6. G. Fraraccioa, A. Bruggerb, R. Bettic, Experimental studies on damage detection in frame structures using vibration measurements. Shock and Vibration 17, 697-721 (2010)

7. J. N. Juang, M. Phan, L. G. Horta, R.W. Longman, Identification of Observer/Kalman FilterMarkov Parameters: Theory and Experiments. Journal of Guidance, Control, and Dynamics 2, 320-329 (1993)

8. R. Brincker, L. Zhang, P. Andersen, Modal identification of output-only systems using frequency domain decomposition. Smart Material and Structure 10, 441-445 (2001)

9. M. De Angelis, H. Lus, R. Betti, R. W. Longman, Extracting Physical Parameters of Mechanical Models From Identified State Space Representations. Journal of Applied Mechanics 69, 617-625 (2002)

10. B. Skočilasová, J. Volek, J. Soukup, Report on Steel Structure Experimental Examination Results. Ústí n. L., (2009) 